\title{
The role of intragestational ghrelin on postnatal development and reproductive programming in mice
}

\author{
P J Torres ${ }^{1, *}$, E M Luque ${ }^{2, *}$, M F Ponzio ${ }^{2,3}$, V Cantarelli ${ }^{4}$, M Diez ${ }^{2}$, S Figueroa ${ }^{2}$, L M Vincenti ${ }^{2}$, \\ $\checkmark \mathrm{P}$ Carlini ${ }^{2,3}$ and A C Martini ${ }^{2,3}$ \\ ${ }^{1}$ Secretaría de Ciencia y Tecnología de la Universidad Nacional de Córdoba (SECyT-UNC), Córdoba, Argentina, \\ ${ }^{2}$ Instituto de Fisiología, Facultad de Ciencias Médicas, Universidad Nacional de Córdoba, Córdoba, Argentina, \\ ${ }^{3}$ Consejo Nacional de Investigaciones Científicas y Tecnológicas (CONICET), INICSA (CONICET-FCM), Córdoba, \\ Argentina and ${ }^{4}$ Fondo Nacional de Ciencia y Tecnología (FONCyT), Córdoba, Argentina
}

Correspondence should be addressed to A C Martini; Email: acmartini2000@yahoo.com

*(P J Torres and E M Luque contributed equally to this work)

\begin{abstract}
The purpose of this study was to evaluate the intragestational role of ghrelin in offspring development and reproductive programming in a mouse model of ghrelin imbalance during pregnancy. Female mice were injected with ghrelin (supraphysiological levels: $4 \mathrm{nmol} /$ animal/day), antagonist (endogenous ghrelin inhibition with $\left(\mathrm{D}-\mathrm{Lys}_{3}\right) \mathrm{GHRP}-6,6 \mathrm{nmol} / \mathrm{animal} / \mathrm{day}$ ) or vehicle (control = normal ghrelin levels) throughout the pregnancy. Parameters evaluated in litters were growth, physical, neurobiological and sexual development and, at adulthood, reproductive function. Litter size and initial weight did not vary between treatments. Male pups from dams treated with ghrelin showed higher body weight increase until adulthood $(31.7 \pm 0.8$ vs control $=29.7 \pm 0.7, n=11-14$ litters/treatment; $P<0.05)$. Postnatal physical and neurobiological development was not modified by treatments. The antagonist accelerated male puberty onset, evidenced as earlier testis descent and increased relative testicular weight (antagonist $=0.5 \pm 0.0 \%$ vs ghrelin $=0.4 \pm 0.0 \%$ and control $=0.4 \pm 0.0 \%, n=5-10$ litters/treatment; $P<0.05)$. At adulthood, these males exhibited lower relative testicular weight and reduced sperm motility $(63.9 \pm 3.6 \%$ vs control $=70.9 \pm 3.3$ and ghrelin $=75.6 \pm 3.0, n=13-15$ animals; $P<0.05)$, without changes in plasma testosterone or fertility. Female pups intragestationally exposed to the antagonist showed earlier vaginal opening (statistically significant only at Day 25) and higher ovarian volume (antagonist $=1085.7 \pm 64.0 \mathrm{~mm}^{3}$ vs ghrelin $=663.3 \pm 102.8 \mathrm{~mm}^{3}$ and control $=512.3 \pm 116.4 \mathrm{~mm}^{3} ; n=4-6$ animals/treatment; $P<0.05$ ), indicating earlier sexual maturation. At adulthood, these females and those exposed to ghrelin showed a tendency to higher percentages of embryo loss and/or foetal atrophy. In conclusion, ghrelin participates in reproductive foetal programming: alterations in ghrelin activity during pregnancy modified body weight increase and anticipated puberty onset, exerting (or tending to) negative effects on adult reproductive function.
\end{abstract}

Reproduction (2018) $156331-341$

\section{Introduction}

Ghrelin (GHRL) is a 28 amino acid peptide that has been linked to reproductive physiology, particularly the modulation of the hypothalamic-hypophysealgonadal axis (Kojima et al. 1999, 2001, Barreiro et al. 2002, Kawamura et al. 2003, Fernández-Fernández et al. 2006, García et al. 2007, Zhang et al. 2007, Tena-Sempere 2008a). Because plasma GHRL concentrations dramatically increase during fasting or undernourishment (Kojima \& Kangawa 2005), this peptide has been proposed as an inhibitory signal for reproductive physiology and behaviour during food scarcity periods (Schneider 2004, Fernández-Fernández et al. 2006, Tena-Sempere 2008a,b, Bertoldi et al. 2011).

A physiological increase of maternal and foetal GHRL levels has been registered during pregnancy in mammals (including humans) (Gualillo et al. 2001, Shibata et al. 2004, Fuglsang et al. 2005, Govoni et al. 2007, Harrison et al. 2007, Palik et al. 2007), which suggests that the peptide may play an important role in gestation. Furthermore, since an active GHRL receptor (GHS-R1a) has been detected in gametes, embryos, placenta, endometrium and fallopian tubes, it has been suggested that GHRL might be one of the numerous peptides that regulate embryo development and/or implantation (Barreiro et al. 2002, 2003, Caminos et al. 2003, Kawamura et al. 2003, Gaytan et al. 2004, 2005, Harrison et al. 2007, Zhang et al. 2007, Du et al. 2010, Steculorum \& Bouret 2011). In a previous study using an in vivo mouse model of intragestational GHRL imbalance (the same one used in the present study), we confirmed that gestational GHRL plays a role in fertilisation, preimplantation embryo development and implantation. 
Indeed, we found some detrimental effects not only with the administration of GHRL (supraphysiological levels) but also with the injection of the antagonist (endogenous ghrelin inhibition), supporting the proposition that GHRL (in 'adequate' concentrations or activity) has a physiological role in early gestational events (Luque et al. 2014).

A few studies also indicate a function of intragestational GHRL in foetal and/or postnatal development. We noticed that chronic food restriction for mouse dams (from Days 1 to 17 of pregnancy), which increases plasma GHRL, provoked developmental defects in the offspring, such as physical, neurobiological and reproductive maturation delay (Torres et al. 2017). It has been demonstrated that maternal GHRL easily crosses the placental blood barrier into the foetal circulation and amniotic fluid in rodents (Kawamura et al. 2003), and gestational food restriction leads to a decrease in offspring body weight at birth (Desai et al. 2005, Chanoine et al. 2006, Wang et al. 2007). However, two studies have reported that the administration of GHRL to pregnant rats from Day 14 to 15 until birth increased offspring body weight (Hayashida et al. 2002, Nakahara et al. 2006).

In a previous study using a GHRL analogue, hexarelin $(200 \mu \mathrm{g} / \mathrm{kg} /$ day $)$, during different stages of pregnancy in mice, we demonstrated that hexarelin, administered during the second or third week of pregnancy (but not during the first week), increased pup body weight gain until adulthood without modifying the initial weight (Luque et al. 2010). It is thus evident that differences between studies depend on the period of gestation in which GHRL rises (naturally or by its exogenous administration) and, probably, on its concentration.

Developmental programming can be defined as a response of mammalian organisms to a specific challenge during a critical development time window (in this case, gestation), which alters the trajectory of development with persistent effects on the offspring phenotype (Rabadan-Diehl \& Nathanielsz 2013). Since the reproductive axis and its hormonal control are largely established during foetal life, they are a target for developmental programming (Chadio \& Kotsampasi 2014).

Although many studies have evaluated the possible effects of intragestational under/over-nutrition on reproductive foetal programming (with negative effects reported at both ends of the nutritional spectrum) (Castellano et al. 2011, Chadio \& Kotsampasi 2014, Zambrano et al. 2014), few investigators have explored the effects of intragestational GHRL imbalances. In general, high doses of GHRL administered to pregnant rats (Hayashida et al. 2002, Nakahara et al. 2006) have induced results comparable to undernourishment protocols (evidenced by an increase in the dams' daily food intake), in which GHRL acts as a starvation signal. Therefore, the information obtained from these studies about the physiological role of GHRL during pregnancy is limited. Moreover, to our knowledge, there is only one study of the effects of maternal GHRL deficiency (comparing homozygote with heterozygote dams) on reproductive foetal programming of female offspring (Martin et al. 2011).

Therefore, the purpose of this study was to evaluate, using a previously validated mouse in vivo approach (Luque et al. 2014), the intragestational role of GHRL on postnatal development, assessing physical, neurobiological and sexual parameters, as well as the reproductive function of the offspring at adulthood.

Since underweight, obesity and polycystic ovarian syndrome are associated with modifications in normal ghrelinaemia (Repaci et al. 2011, GoebelStengel et al. 2013), it is important to recognise the possible consequences of these imbalances in offspring development.

\section{Materials and methods}

\section{Animals}

Experiments were conducted in accordance with the Guide for the Care and Use of Laboratory Animals of the Medical School of the Universidad Nacional de Córdoba (UNC-RHCS 674/09). Its animal ethics committee approved the protocols used in this study (April 14, 2014).

We used adult (60-80 days; $30-35 \mathrm{~g}$ ) female inbred Albino Swiss mice (N:NIH) maintained on a 14:10-h light:darkness regime at $23 \pm 2^{\circ} \mathrm{C}$, with access to water and food (Grupo Pilar-Gepsa, Cordoba, Argentina) ad libitum. It should be noted that our previous experiments established that the doses of GHRL or antagonist used in this study do not significantly modify the daily food intake or body weight (Luque et al. 2014). Nevertheless, results of food intake and dam body weight from this specific study are presented in 'Results' section.

\section{Chemicals}

GHRL (Innovagen, Lund, Sweden) and its antagonist, Ant: (D-Lys ${ }_{3}$ )GHRP-6 (Sigma-Aldrich), were dissolved in isotonic solution $(0.9 \%$ CINa solution) and administered by subcutaneous injection twice a day (with half of the daily dose in each injection, at 09:00 h and 17:00 h). Control animals received the vehicle in the same regimen. The GHRL doses used in this study were established based on its ability to increase growth hormone secretion from a dose-response curve previously performed and published by our group (Bertoldi et al. 2011). Concordantly, the selected dose of the antagonist was previously demonstrated to inhibit the effects of endogenous hyperghrelinaemia or exogenously administered GHRL, which makes this option an effective GHRL antagonist protocol (Bertoldi et al. 2011, Luque et al. 2014). Plasma GHRL results in dams are shown in the corresponding section. This parameter was evaluated by means of a specific ELISA kit (see below). 


\section{Experimental groups}

From the day of copula confirmation (by observation of vaginal plug or spermatozoa in vaginal smears) and throughout pregnancy, female mice were subjected to one of the following treatments:

- Ghrelin (GHRL): $4 \mathrm{nmol} /$ animal/day of GHRL dissolved in $0.2 \mathrm{~mL}$ of isotonic solution (i.e. treatment that induces supraphysiological levels of ghrelin).

- Antagonist (Ant): $6 \mathrm{nmol} /$ animal/day of (D-Lys ${ }_{3}$ GHRP-6 (GHRL antagonist) dissolved in $0.2 \mathrm{~mL}$ of isotonic solution (i.e. treatment that inhibits endogenous ghrelin actions).

- Control (C): $0.2 \mathrm{~mL}$ of isotonic solution/animal/day (i.e. physiological ghrelin levels).

Drugs were administered twice a day and the treatment stopped when delivery was confirmed. The offspring of these dams did not receive any further treatment.

\section{Effects of intragestational GHRL imbalance on physical, neurobiological and sexual development of the offspring}

Litter size and weight were recorded $24 \mathrm{~h}$ after birth (postnatal Day $1=$ pnd 1 ). To avoid differences in body weight evolution during lactation due to differences in litter size, four male and four female pups per dam were randomly selected (the remaining pups in the litter were killed). The reduced litter (8 pups/dam) was weighed again and then once a week until adulthood, differentiating sexes (quantified as mean of the male or the female litter and finally expressed in 'Results' section as mean of litters/group). Results were expressed as initial weight, body weight evolution and body weight increase (absolute and as percentage).

Physical and neurobiological development was determined in the entire litter (i.e. without differentiating sexes) (following Santillán et al. 2010, Luque et al. 2010) as follows:

\section{Physical development}

Parameters evaluated were bilateral pinna detachment (unfolding of external ear, from pnd 1 to pnd 6), low incisors eruption (emergence from the gingival, from pnd 8 to pnd 13) and eyes opening (from pnd 10 to pnd 16) (Kihara et al. 2001, Bowers et al. 2004).

\section{Neurobiological development}

Three different reflex/behavioural tests were performed: (a) cliff avoidance: each animal was placed on a table edge with forepaws and nose over the edge (height $20 \mathrm{~cm}$ ). Time required to complete backing and turning away from the edge was assessed. The number of animals with a successful response within $30 \mathrm{~s}$ was recorded. This parameter is considered a marker of maturity in sensory and motor functions associated with development and was evaluated at pnd 8 (Yoshida et al. 2000); (b) negative geotaxis: pups were placed in a head down position on a $45^{\circ}$ inclined cardboard surface, and the time required to complete a $180^{\circ}$ turn was measured. The number of mice with a successful response within 30 s was recorded.
This test reflects the function of the vestibular system and was evaluated on pnd 9 (Metz and Schwab 2004) and (c) surface righting reflex: each mouse was held on its back on a flat surface for $4 \mathrm{~s}$ and subsequently released. The number of animals that regained all four paws in contact with the surface within $2 \mathrm{~s}$ was recorded. This is a standard test for labyrinth function and body righting mechanism and was evaluated on pnd 10 (Vorhees et al. 1979).

\section{Sexual development}

Puberty onset was determined in males when both testicles descended and in females by day of vaginal opening. Additionally, oestrus cyclicity was evaluated from vaginal opening until adulthood by means of vaginal smears. The length of a cycle was measured from the first day of oestrus until the day before the next oestrus; only complete cycles were considered for statistics. A group of male and female pups were killed at pnd 19 and pnd 23 respectively, to weigh/ measure their gonads. Testes were weighed using a digital scale. Ovarian volume was calculated by fixing the ovaries (in Bouin solution), including them in paraffin and performing multiple serial cuts to the gonad. Under an optic microscope, one section was randomly selected from the first eight sections, and measured; counting from that section onwards, every eighth section was also measured. Each evaluated section was measured using a scale incorporated into the microscope, assessing the perpendicular axes ( $\mathrm{a}$ and $\mathrm{b}$ ). According to the Cavalier principle, ovarian volume was calculated as follows: $V=\sum a i \times T \times 1 / f$, with 'ai' being the area of each section $(a i=(\pi / 4) a . b), ' T^{\prime}$ the thickness of the sections $(7 \mu \mathrm{m})$ and ' $f$ ' the fraction of the sections measured ( 1 from eight in our study).

\section{Effects of intragestational GHRL imbalance on the reproductive function of offspring in adulthood}

At adulthood (60 days), the reproductive function of the offspring was evaluated as follows:

\section{Female evaluation}

Females were allowed to mate with control males (without treatment) and killed to evaluate reproductive parameters at Day 18 of gestation as follows:

Number of corpora lutea Both ovaries were dissected and the number of fresh corpora lutea/female was evaluated under a stereoscopic magnifying glass (Luque et al. 2014). In previous experiments performed in our laboratory, we observed, under controlled conditions, an equal number of corpora lutea and foetuses in more than $80 \%$ of the females. We therefore consider this parameter to be an acceptable sign of ovulation rate (Puechagut et al. 2012, Luque et al. 2014).

Atrophied foetuses The uterus was extruded and the number and the weight of the foetuses were evaluated. Foetuses visually smaller than normal (two thirds or even smaller) were counted as 'atrophied' (Luque et al. 2014). This parameter was calculated not only for each female (number of atrophied foetuses/female) but also for each treatment, recording the 
percentage of dams/treatment that exhibited some degree of foetal atrophy.

Embryo loss Once the number of corpora lutea and foetuses (including atrophied ones) were evaluated at gestational Day 18, an index between these two variables was calculated by the following formula: $100-$ (number of foetuses $\times 100$ / number of corpora lutea) (Luque et al. 2014). When more corpora lutea than foetuses were found, we considered that some alteration had occurred in the reproductive process; we named this event 'embryo loss' and expressed the variable as a percentage. Again, this parameter was calculated not only for each female (percentage of embryo loss/female) but also per treatment, i.e. recording the percentage of females/treatment that exhibited more corpora lutea than foetuses (independently of the index value).

\section{Male evaluation}

Fertility At adulthood, male pups were allowed to mate with control females (without any treatment). At pregnancy Day 18, the females were killed to evaluate percentages of pregnancy and number and weight of foetuses. We also evaluated the proportion of embryo loss and atrophied foetuses as described above.

Plasma testosterone Male pups were killed at adulthood by decapitation and blood was collected in tubes with EDTA and centrifuged at $120 \mathrm{~g}$ for $30 \mathrm{~min}$. Plasma was stored at $-20^{\circ} \mathrm{C}$ until processing. Testosterone concentration was determined with an in-house enzyme immunoassay using a polyclonal anti-testosterone antibody, testosterone standard and their corresponding horseradish peroxidase conjugates (testosterone R156/7, Department of Population Health and Reproduction, C. Munro, UC Davis, CA, USA). Briefly, flat bottom microtitre plates (Nunc Maxisorp, VWR, Mississauga, ON, Canada) were first coated with $50 \mu \mathrm{L}$ of the anti-testosterone antibody diluted in coating buffer $(50 \mathrm{mM}$ bicarbonate buffer, $\mathrm{pH} 9.6 ; 1: 10,500)$, covered with acetate sealers to prevent evaporation and incubated overnight at $4{ }^{\circ} \mathrm{C}$. After 16-24h, plates were washed to remove any unbound antibody with $0.02 \%$ Tween 20 solution using a Bio-Tek ELx 405VR microplate washer (Bio-Tek Instruments). Immediately after washing, $50 \mu \mathrm{L}$ of plasma samples, standards and controls were added in duplicates, followed by $50 \mu \mathrm{L}$ of horseradish peroxidase conjugate diluted in EIA buffer $(1: 20,000)$. Plates were then covered and incubated at room temperature for $2 \mathrm{~h}$. Following incubation, the plates were washed and blotted dry, and $100 \mu \mathrm{L}$ of substrate solution $(50 \mathrm{mM}$ citrate, $1.6 \mathrm{mM}$ hydrogen peroxide and $0.4 \mathrm{mM} \mathrm{2,20-azino-di-(3-ethylbenz-}$ thiazoline sulfonic acid) diammonium salt, $\mathrm{pH}$ 4.0) were added to each well. Absorbance was measured at $405 \mathrm{~nm}$ using a microplate reader (Thermo Electron Corporation, USA). The assay sensitivity was $0.047 \mathrm{ng} / \mathrm{mL}$. The intraassay and inter-assay coefficients of variation were less than $10 \%$ and $15 \%$, respectively. Cross-reactivity values were 5 - $\alpha$-dihydrotestosterone $(57.4 \%)$, androstenedione $(0.27 \%)$, androsterone $(0.04 \%)$, cholesterol $(0.03 \%)$ and $<0.02 \%$ with all other steroids tested.
Sperm functional activity Caudal epididymal spermatozoa were obtained as previously described (Fiol de Cuneo et al. 1994). Sperm concentration and motility were quantified in a Makler counting chamber (Makler 1980) (SefiMedical Instruments, Israel). Motility was expressed as a percentage of motile cells (progressive plus non-progressive gametes).

Sperm viability was assessed using the supravital stain, Hoechst 33258, as previously described (Kovács \& Foote 1992) and evaluated with an epifluorescence microscope (Zeiss, Germany). Results were expressed as a percentage of viable cells.

The percentage of immature gametes was evaluated by quantifying the percentage of spermatozoa showing the bent morphology and/or a persistent cytoplasmic drop (Bedford et al. 1973, Cooper 1998, Cornwall et al. 1988).

The response to the hypoosmotic swelling test (PRO) was assessed as previously described (Fiol de Cuneo et al. 1994), incubating spermatozoa in hypoosmotic solution and quantifying those that reacted to this osmotic challenge 40 min later.

Acrosomal reaction was evaluated by the Coomassie blue technique (Larson \& Miller 1999), and the results were expressed as the percentage of spermatozoa with intact acrosome.

Ghrelin determinations Another group of dams was killed (at Day 8 of gestation) by decapitation and blood was collected in tubes with EDTA and centrifuged at $120 \mathrm{~g}$ for $30 \mathrm{~min}$. Plasma was then collected and stored at $-20^{\circ} \mathrm{C}$ until processing. Ghrelin concentrations were determined using a specific commercial ELISA kit (EK-031-31, Phoenix Pharmaceuticals Inc., CA, USA) following the manufacturer's instructions. This kit has a sensitivity of $0.12 \mathrm{ng} / \mathrm{mL}$ and a range of $0-100 \mathrm{ng} /$ $\mathrm{mL}$ (linear range $0.12-1.26 \mathrm{ng} / \mathrm{mL}$ ). The intra-assay and inter-assay coefficients of variation were less than $10 \%$ and $15 \%$, respectively.

\section{Statistical analysis}

In general, results were expressed as mean \pm S.E.M. and were analysed by one-way ANOVA with LSD Fisher as a post hoc comparison analysis. Results from parameters that were evaluated several times in the same litter (dam food intake and body weight, pup body weight, bilateral pinna detachment, lower incisor eruption, eyes opening, testis descent and vaginal opening) were evaluated by repeatedmeasures ANOVA (with evaluation day and treatment as fixed effects and litter as random effect), using LSD Fisher as post hoc. To apply these tests, the variance homogeneity and Gaussian distribution (by modified Shapiro-Wilk) were confirmed. Parameters expressed as a percentage (percentage of females with foetal atrophy/treatment and percentage of females with embryo loss/treatment) were analysed by chi-square test. In all cases, $P$ values under 0.05 were considered statistically significant. Statistical analyses were performed with Infostat 2016p (Infostat Group, Facultad de Ciencias Agropecuarias - Universidad Nacional de Córdoba, Argentina). 
Table 1 Food intake and body weight increase during pregnancy of dams treated with ghrelin or an antagonist.

\begin{tabular}{|c|c|c|c|}
\hline Variable/day of pregnancy & Control $(n=5)$ & Ghrelin (4 nmol/animal/day) $(n=5)$ & Antagonist $(6 \mathrm{nmol} /$ animal $/$ day $)(n=6)$ \\
\hline \multicolumn{4}{|l|}{ Daily food intake (g) } \\
\hline 1 & $3.28 \pm 0.34^{*}$ & $3.23 \pm 0.41^{*}$ & $2.84 \pm 0.32^{*}$ \\
\hline 7 & $4.15 \pm 0.37^{\#}$ & $4.71 \pm 0.57^{\#}$ & $4.44 \pm 0.66^{\#}$ \\
\hline 14 & $5.63 \pm 0.53$ & $5.02 \pm 0.44$ & $5.27 \pm 0.52$ \\
\hline 18 & $5.75 \pm 0.38$ & $5.27 \pm 1.56$ & $6.33 \pm 0.47$ \\
\hline \multicolumn{4}{|l|}{ Body weight (g) } \\
\hline 1 & $25.83 \pm 1.25^{\circ}$ & $24.88 \pm 1.78^{\circ}$ & $23.92 \pm 1.57^{\circ}$ \\
\hline 7 & $26.61 \pm 1.30^{\circ}$ & $26.31 \pm 1.86^{\circ}$ & $24.52 \pm 1.74^{\circ}$ \\
\hline 16 & $38.75 \pm 1.60^{@}$ & $35.57 \pm 3.81^{@}$ & $34.62 \pm 3.22^{@}$ \\
\hline 19 & $46.19 \pm 1.94$ & $41.66 \pm 7.15$ & $45.72 \pm 2.90$ \\
\hline
\end{tabular}

Ghrelin or its antagonist ((D-Lys3)GHRP-6) were administered (s.c.) during the whole pregnancy in two injections/day. Control dams were injected with vehicle in the same regimen (isotonic solution). Values are expressed as mean \pm S.E.M. In parenthesis: number of dams evaluated. There are no differences between treatments. Differences between days, $P<0.001$ : *Day 1 vs Days 7, 14 and 18 ; *Day 7 vs Days 14 and 18 ; ${ }^{\circ}$ Days 1 and 7 vs Days 16 and 19; ${ }^{\circ}$ Day 16 vs Day 19.

\section{Results}

Dams were treated with GHRL, Ant or the vehicle throughout gestation. To corroborate previous results (Luque et al. 2014), we evaluated food intake during pregnancy in an initial group of dams. As expected, food intake increased along with pregnancy, but did not differ between groups (Table 1). Similar results were observed for the parameter 'body weight', which increased during pregnancy but was not different between treatments (Table 1). To biochemically validate our model, the ghrelin plasma levels in the dams were evaluated. Concentrations detected were C: $15.6 \pm 2.2 \mathrm{ng} / \mathrm{mL}$, GHRL: $42.0 \pm 8.0 \mathrm{ng} / \mathrm{mL}$ and Ant: $11.8 \pm 1.0 \mathrm{ng} / \mathrm{mL} \quad(n=6-7 \quad$ dams $/$ treatment; $P=0.002$ GHRL vs $C$ and Ant).

\section{Effects of intragestational GHRL imbalance on physical, neurobiological and sexual development of the offspring}

Neither litter size $(C=10.10 \pm 1.02, G H R L=10.17 \pm 0.51$ and Ant $=10.76 \pm 0.38 ; \quad n=10-17$ litters/treatment; $P>0.05$ ) nor pup initial body weight (pnd 1) were modified by these treatments $(C=1.63 \pm 0.06 \mathrm{~g}$, $\mathrm{GHRL}=1.66 \pm 0.03 \mathrm{~g}$ and Ant $=1.59 \pm 0.05 \mathrm{~g}$, $n=10-17$ litters/treatment; $P>0.05$ ). Pup body weight was greater in pups from dams treated with GHRL, especially in males, in which differences remained significant from pnd 35 onward (Fig. 1). In fact, these pups also exhibited a significantly higher increase in body weight (calculated as final body weight-initial body weight: $\mathrm{GHRL}=31.7 \pm 0.8$ vs $\mathrm{C}=29.7 \pm 0.7$, $n=11 / 14$ litters/treatment; $P=0.035$ ). Female pups showed a similar tendency, but the values were statistically significant only on pnd 35 (Fig. 1).

Physical development, evaluated as bilateral pinna detachment, eruption of lower incisors and eyes opening, was not affected by treatments. As expected, the percentage of pups positive for each of these parameters increased with age (i.e. postnatal day)
(Fig. 2). Neurobiological maturation was not altered by treatments either (Table 2).

Male pups from dams treated with Ant showed earlier puberty onset, determined as time of testis descent. These differences were statistically significant at pnd 19, 20 and 21 (Fig. 3). Concordantly, these pups exhibited higher relative testicular weight compared to other

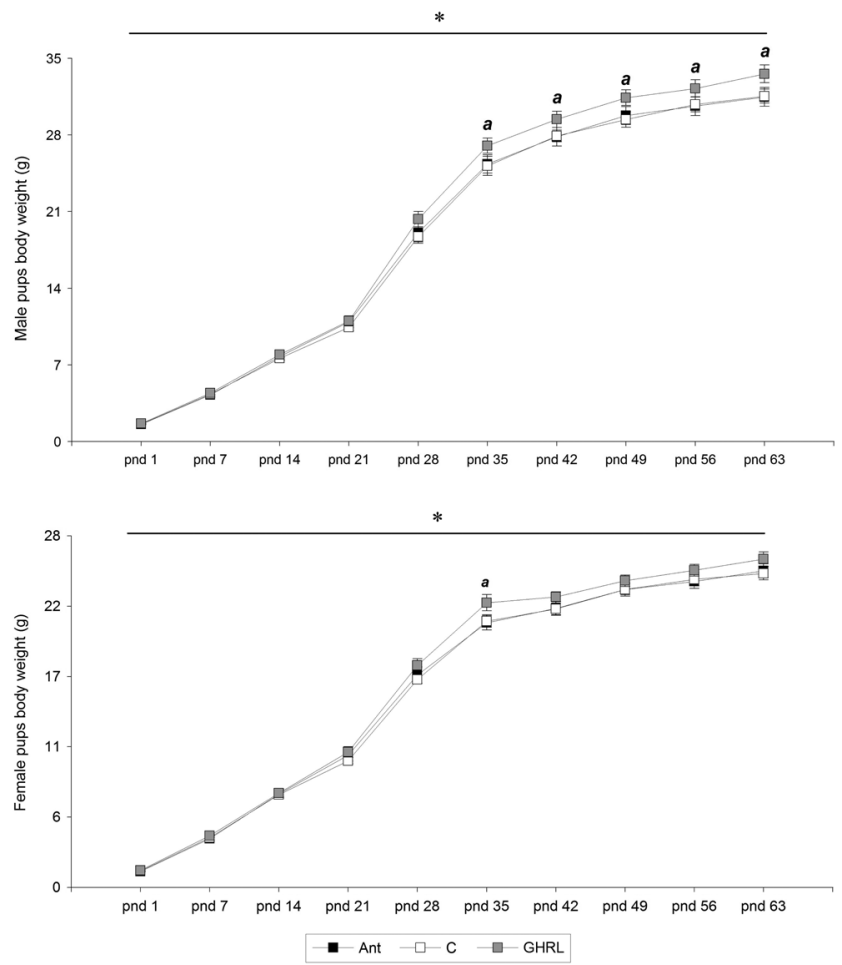

Figure 1 Body weight increase of male and female pups from birth (pnd 1 = postnatal Day 1 ) to adulthood (pnd 63). Dams were treated throughout pregnancy with ghrelin (GHRL: $4 \mathrm{nmol} /$ animal/day), an antagonist (Ant: (D-Lys3)GHRP-6; $6 \mathrm{nmol} /$ animal/day) or vehicle (C: isotonic solution). Values are expressed as mean \pm S.E.M. Number of litters evaluated: 11 C, 14 GHRL and 14 Ant (8 pups/litter; 4 males and four females). ${ }^{*} P<0.0001$ between all postnatal days. Males: a: $P=0.028$ GHRL vs $C$ and Ant; females: $\mathrm{a}=0.047 \mathrm{GHRL}$ vs $\mathrm{C}$ and Ant. 

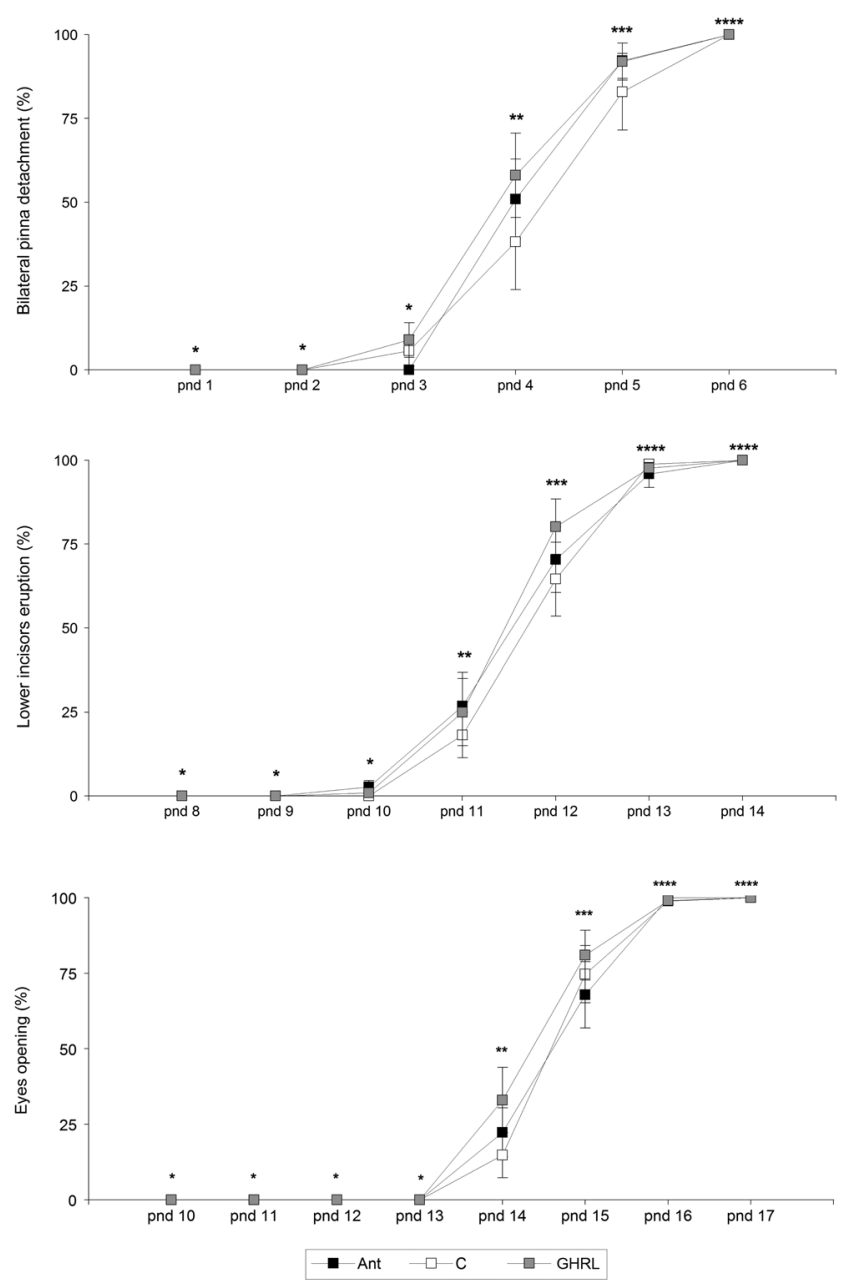

Figure 2 Percentage of pups/treatment positive for the physical parameters evaluated. Dams were treated throughout pregnancy with ghrelin (GHRL: $4 \mathrm{nmol} /$ animal/day), an antagonist (Ant: (D-Lys3) GHRP-6; $6 \mathrm{nmol} /$ animal/day) or vehicle (C: isotonic solution). Values are expressed as mean \pm S.E.M. of the percentage of pups positive for each parameter. Number of litters evaluated: 11-14/treatment (8 pups/litter; four males and four females). Differences between postnatal days $(P<0.0001):{ }^{*}$ vs $* *$ vs $* * *$ vs $* * *$.

groups (pnd 19: Ant $=0.5 \pm 0.0 \%$ vs $\mathrm{GHRL}=0.4 \pm 0.0 \%$ and $\mathrm{C}=0.4 \pm 0.0 \%, n=5-10$ litters/treatment; $P=0.038$ ). It is important to highlight that pups exposed to intragestational GHRL also showed a tendency to earlier testis descent than C-treated pups.
Regarding puberty onset in female pups (i.e. day of vaginal opening), treatments with GHRL and Ant were both characterised by earlier vaginal opening. Nevertheless, the differences reached statistical significance only at pnd 25 (Fig. 3). Ovary volume at pnd 23 was significantly higher in female pups exposed to Ant (Ant $=1085.7 \pm 64.0 \mathrm{~mm}^{3}$ vs $\mathrm{GHRL}=663.3 \pm 102.8 \mathrm{~mm}^{3}$ and $\mathrm{C}=512.3 \pm 116.4 \mathrm{~mm}^{3}$; $n=4-6$ animals/treatment; $P=0.006$ ).

No differences were detected in the number and length of oestrous cycles (number of oestrous cycles from vaginal opening until adulthood: $C=3.1 \pm 0.2$, $\mathrm{GHRL}=4.0 \pm 0.4$ and $\mathrm{Ant}=3.4 \pm 0.3$. Duration of oestrous cycles: $\mathrm{C}=7.0 \pm 0.4, \mathrm{GHRL}=6.4 \pm 0.6$ and $\mathrm{Ant}=6.7 \pm 0.4$. Length of oestrus: $\mathrm{C}=1.7 \pm 0.1, \mathrm{GHRL}=1.6 \pm 0.1$ and Ant $=1.8 \pm 0.2 ; n=8-12$ litters/treatment; 2 female pups/ litter; $P>0.05)$.

\section{Effects of intragestational GHRL imbalance on reproductive function of the offspring at adulthood}

At adulthood, male pups from dams treated with Ant exhibited a significantly lower relative testicular weight than those receiving intragestational GHRL. These animals also showed a decrease in sperm motility compared to GHRL or vehicle (Table 3). Nevertheless, these differences did not impact male fertility, which was similar in control pups (percentage of pregnancy: $\mathrm{C}=88.8$ and $\mathrm{Ant}=88.8$; litter size: $\mathrm{C}=12.0 \pm 0.4$ and Ant $=12.9 \pm 0.6$; pups initial weight: $C=0.97 \pm 0.03$ and Ant $=0.95 \pm 0.03 ; \quad$ embryo loss: $C=2.1 \pm 2.1$ and $A n t=3.5 \pm 2.3$; foetal atrophy: $C=0.5 \pm 0.3$ and Ant $=0.1 \pm 0.1 ; \quad P>0.05, \quad n=9$ males/treatment). No differences were detected either in the testosterone plasma levels of these animals $(C=2.74 \pm 1.18 \mathrm{ng} / \mathrm{mL}$, $\mathrm{GHRL}=1.35 \pm 0.67 \mathrm{ng} / \mathrm{mL}$ and $\mathrm{Ant}=2.61 \pm 0.88 \mathrm{ng} / \mathrm{mL}$; $n=4-7$ males/treatment, $P>0.05$ ).

Reproductive parameters of female pups at adulthood (Table 4) did not show any differences in latency to mate acceptance, ovulation rate or litter size. Although females exposed to intragestational Ant and GHRL exhibited a higher tendency for embryo loss or foetal atrophy, results did not reach statistical significance (Table 4).

\section{Discussion}

In this study, we aimed to evaluate the intragestational role of GHRL on the postnatal development of offspring,

Table 2 Neurobiological parameters of pups from dams treated with intragestational ghrelin or antagonist.

\begin{tabular}{lrcr}
\hline Variable & Control $(n=12)$ & Ghrelin $(4 \mathrm{nmol} /$ animal/day $)(n=16)$ & Antagonist $(6 \mathrm{nmol} / \mathrm{animal} /$ day $)(n=16)$ \\
\hline Cliff avoidance $(\%)$ & $98.9 \pm 1.0$ & $96.9 \pm 2.4$ & $99.2 \pm 0.8$ \\
Negative geotaxis $(\%)$ & $96.2 \pm 1.9$ & $96.7 \pm 2.3$ & $99.2 \pm 0.8$ \\
Surface righting reflex $(\%)$ & $100.0 \pm 0.0$ & $99.2 \pm 0.8$ & $99.2 \pm 0.8$ \\
\hline
\end{tabular}

Ghrelin or its antagonist ((D-Lys3)GHRP-6) were administered (s.c.) during the whole pregnancy in two injections/day. Control dams were injected with the vehicle in the same regimen (isotonic solution). Pups did not receive further treatment after birth. Neurobiological parameters, cliff avoidance, negative geotaxis and surface righting reflex were evaluated on postnatal days 8,9 and 10 respectively. Values are expressed as mean \pm S.E.M. of the percentage of pups positive for this parameter. In parenthesis: number of litters evaluated (8 pups/litter). 
Table 3 Morphometric parameters and sperm functional activity of pups from dams treated with intragestational ghrelin or an antagonist.

\begin{tabular}{|c|c|c|c|}
\hline Variable & Control $(n=13)$ & Ghrelin (4 nmol/animal/day) $(n=15)$ & Antagonist $(6 \mathrm{nmol} /$ animal $/$ day $)(n=15)$ \\
\hline Body weight (g) & $32.95 \pm 0.92$ & $33.51 \pm 0.72$ & $34.03 \pm 0.88$ \\
\hline Testicular weight (g) & $0.19 \pm 0.01$ & $0.21 \pm 0.01$ & $0.19 \pm 0.01$ \\
\hline Relative TW (\%) & $0.59 \pm 0.02$ & $0.63 \pm 0.02$ & $0.57 \pm 0.01^{*}$ \\
\hline Seminal vesicles weight (g) & $0.33 \pm 0.02$ & $0.34 \pm 0.02$ & $0.33 \pm 0.02$ \\
\hline Relative SVW (\%) & $1.01 \pm 0.05$ & $1.03 \pm 0.07$ & $0.99 \pm 0.07$ \\
\hline Sperm concentration $\left(\times 10^{6} / \mathrm{mL}\right)$ & $16.34 \pm 2.16$ & $16.99 \pm 1.99$ & $14.74 \pm 1.44$ \\
\hline Motile spermatozoa (\%) & $70.85 \pm 3.33$ & $75.56 \pm 2.98$ & $63.87 \pm 3.64^{\#}$ \\
\hline Immature spermatozoa (\%) & $14.46 \pm 2.17$ & $11.33 \pm 1.22$ & $14.33 \pm 2.52$ \\
\hline Viability $(\%)$ & $84.00 \pm 1.33$ & $81.20 \pm 2.14$ & $84.87 \pm 1.43$ \\
\hline PRO (\%) & $78.77 \pm 2.22$ & $81.13 \pm 2.79$ & $78.47 \pm 2.98$ \\
\hline Acrosomal reaction $(\%)$ & $89.00 \pm 3.13$ & $87.20 \pm 1.89$ & $90.40 \pm 2.07$ \\
\hline
\end{tabular}

Ghrelin (GHRL) or its antagonist (Ant: (D-Lys3)GHRP-6) were administered (s.c.) during the whole pregnancy in two injections/day. Control dams were injected with the vehicle in the same regimen (isotonic solution). Pups did not receive further treatment after birth. At adulthood, morphometric (absolute and relative to body weight) and sperm functional parameters were evaluated. Values are expressed as mean \pm S.E.M. In parenthesis: number of animals evaluated (two male pups at adulthood/litter).

${ }^{*} P=0.041$ vs GHRL; ${ }^{*} P=0.028$ vs $\mathrm{C}$ and GHRL.

$\mathrm{PRO}$, hypoosmotic swelling test (\% of spermatozoa reactive to hyposmotic solution); acrosome reaction (\% of spermatozoa with an intact acrosome); relative SVW, relative seminal vesicles weight; motile spermatozoa (percentage of progressive spermatozoa); immature spermatozoa (\% of spermatozoa bended and/or with a cytoplasmic drop); viability (\% of alive spermatozoa); relative TW, relative testicular weight.
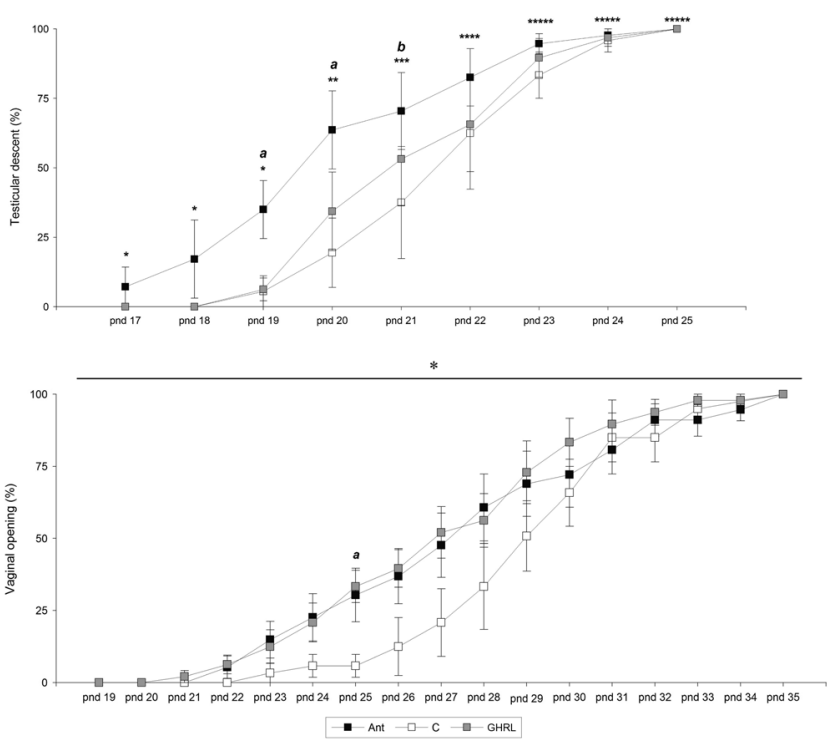

Figure 3 Percentage of pups/treatment positive for the parameter testicular descent or vaginal opening. Dams were treated throughout pregnancy with ghrelin (4 nmol/animal/day), an antagonist ((D-Lys3) GHRP-6; $6 \mathrm{nmol} / \mathrm{animal} /$ day) or vehicle (isotonic solution). Values are expressed as mean \pm S.E.M. of the percentage of pups positive for each parameter. Number of litters evaluated: 11-14/treatment (8 pups/ litter; four males and four females). Testicular descent; differences between treatments: a: $P=0.046$ Ant vs $C$ and GHRL; b: $P=0.046$ Ant vs $C$; differences between postnatal days: $P<0.0001: *$ vs ** vs $* * *$ vs $* * * *$ vs $* * * * *$. Vaginal opening; differences between treatments: a: $P=0.033$ Ant and GHRL vs $C$; differences between postnatal days: $* P<0.0001$ pnd 19 to 21 vs pnd 23 to 35 , pnd 22 vs pnd 24 to 35 , pnd 23 vs pnd 25 to 35 , pnd 24 vs pnd 26 to 35 , pnd 25 and 26 vs pnd 27 to 35 , pnd 27 vs pnd 28 to 35 , pnd 28 vs pnd 29 to 35 , pnd 29 vs pnd 30 to 35 , pnd 30 vs pnd 31 to 35 , pnd 31 vs pnd 33 to 35 , pnd 32 vs pnd 35 . with an emphasis on reproductive programming. For this purpose, we used a mouse model that had been already validated (Bertoldi et al. 2011, Luque et al. 2014). This model includes a group with supraphysiological concentrations of GHRL (i.e. GHRL), one with endogenous GHRL inhibition (i.e. Ant) and one with the 'normal' concentrations of the peptide (i.e. the $\mathrm{C}$ group). Using this approach of GHRL imbalance, we can explore the physiological role of the peptide on foetal programming.

Apart from the increase in pup body weight until adulthood exerted by intragestational exposure to GHRL, the main finding of our study was that GHRL imbalance during pregnancy was able to modify the puberty onset and reproductive function of pups reaching adulthood. These effects were particularly evident in male pups and in the Ant group. Overall, these results support the hypothesis that intragestational GHRL programmes the time of puberty onset and that changes in 'normal' levels (or activity) of GHRL during pregnancy might alter (i.e. accelerate) the timing of this process. This may or may not be interpreted as a 'positive' adaptation, because reproductive function at adulthood was (slightly) poorer in animals exposed to this gestational imbalance.

Our study found that intragestational treatment with Ant (and a similar tendency with GHRL) accelerated sexual development of male pups, evidenced as earlier testis descent and higher testicular weight at peripubertal stages. In female pups, the external signs of puberty onset (i.e. vaginal opening) tended to appear earlier in animals exposed to intragestational Ant or GHRL, but, compared to control animals, varied significantly only at pnd 25. Higher ovary volume was detected in pups born from dams treated with Ant.

There are two arguments that might sustain these results: First, 'intragestational GHRL imbalance modifies 
Table 4 Morphometric and reproductive parameters of female pups from dams treated with intragestational ghrelin or an antagonist.

\begin{tabular}{|c|c|c|c|}
\hline Variable & Control $(n=19)$ & $\begin{array}{l}\text { Ghrelin (4 nmol/animal/day) } \\
\qquad(n=19)\end{array}$ & $\begin{array}{l}\text { Antagonist ( } 6 \mathrm{nmol} / \text { animal/day) } \\
\qquad(n=22)\end{array}$ \\
\hline Body weight (g) & $48.13 \pm 1.36$ & $51.93 \pm 1.29$ & $52.69 \pm 1.91$ \\
\hline Days until mate acceptance & $2.74 \pm 0.25$ & $2.37 \pm 0.30$ & $3.37 \pm 0.47$ \\
\hline Ovulation rate & $12.58 \pm 0.57$ & $12.74 \pm 0.38$ & $12.32 \pm 0.42$ \\
\hline Viable litter size & $12.00 \pm 0.52$ & $11.42 \pm 0.37$ & $10.86 \pm 0.70$ \\
\hline Pups weight $(\mathrm{g})$ & $0.84 \pm 0.03$ & $0.90 \pm 0.03$ & $0.81 \pm 0.04$ \\
\hline Foetal atrophy/female & $0.26 \pm 0.10$ & $0.42 \pm 0.16$ & $0.91 \pm 0.46$ \\
\hline Females with foetal atrophy/treatment $(\%)$ & 26.30 & 31.60 & 36.40 \\
\hline Embryo loss/female $(\%)$ & $2.39 \pm 1.24$ & $6.06 \pm 2.67$ & $4.33 \pm 1.63$ \\
\hline Females with embryo loss/treatment (\%) & 21.10 & 31.60 & 31.80 \\
\hline
\end{tabular}

Ghrelin or its antagonist ((D-Lys3)GHRP-6) were administered (s.c.) during the whole pregnancy in two injections/day. Control dams were injected with the vehicle in the same regimen (isotonic solution). Pups did not receive further treatment after birth. At adulthood, these females were mated with males without treatment (Day 1 of pregnancy: visible vaginal plug or spermatozoa in vaginal smear). At gestation Day 18, females were killed and reproductive parameters evaluated. Values are expressed as mean \pm S.E.M. In parenthesis: number of animals evaluated (2 female pups at adulthood/litter). Body weight: evaluated at pregnancy Day 18; ovulation rate: estimated by the number of corpora lutea at ovaries; foetal atrophy: number of foetuses abnormally smaller than the others; females with foetal atrophy: percentage of females with one or more atrophied foetuses; embryo loss: higher number of corpora lutea than total foetuses (100 - (number foetuses $\times 100 /$ corpora lutea)); females with embryo loss: percentage of females with embryo loss.

the hypothalamic Kiss-1 system': it is accepted that kisspeptins are the gatekeeper for puberty onset (or at least, essential amplifiers) and are necessary modulators for GnRH secretion (reviewed in: Chadio \& Kotsampasi 2014, De Bond \& Smith 2014, Avendaño et al. 2017). It has also been recognised that the kisspeptin system links puberty onset/fertility with energy balance (reviewed in: Chadio \& Kotsampasi 2014, De Bond \& Smith 2014, Avendaño et al. 2017). There is considerable evidence that maternal underfeeding, as well as overfeeding, may influence the hypothalamic circuits responsible for reproduction control and the distribution pattern of $\mathrm{GnRH}$ neurons, thus affecting puberty and later fertility (Iwasa et al. 2010, Castellano et al. 2011, Chadio \& Kotsampasi 2014, Zambrano et al. 2014). Moreover, a link between GHRL and the Kiss-1 system has been well established. It has been demonstrated, by in vitro and in vivo models, that GHRL suppresses the amplitude and/or duration of LH peaks by reducing GnRH release, presumably acting by inhibiting the Kiss-1 system (Fernández-Fernández et al. 2005, Martini et al. 2006). Since it is possible that the Kiss-1 system might be differentially programmed in our model of GHRL imbalance, we are currently developing new experiments to evaluate the expression of kisspeptin mARN in two hypothalamic nuclei of male/ female pups.

Second, 'gonads are a target for intragestational GHRL programming': In rodents, primordial germ cells migrate to the gonadal ridge around gestation Day 12-13. At gestation Day 15.5, these germ cells proliferate and enter meiosis, becoming sex-specific primordial cells (reviewed in Chadio \& Kotsampasi 2014). Since the number of female germinal cells is limited by those that enter meiosis, any alteration at this period of foetal development may have longlasting effects on female progeny (reviewed in Chadio \& Kotsampasi 2014). Specifically in males, Sertoli cells could also provide a target for programming, as they proliferate during the foetal/neonatal and peripubertal periods. During these stages, the mature adult size of the testis and their capacity to produce sperm are established (Orth et al. 1988, Chadio \& Kotsampasi 2014). In fact, a low number of Sertoli cells and changes in the testicular structure have been observed in adult rats born from dams that underwent undernourishment during gestation and lactation (Genovese et al. 2010). Moreover, in prepubertal rats, GHRL has been shown to inhibit immature germ cell proliferation through inhibition of the stem cell factor, which is also a key signal for spermatogenesis (Barreiro et al. 2004). Whether such a negative effect of increased GHRL may occur in testicular foetal development remains unknown. The reduced testicular weight at adulthood observed in males exposed to intragestational Ant supports a possible deleterious programming effect at gonadal level. We are currently performing histological analysis of peripubertal and adult offspring's testis in order to elucidate these aspects.

In male pups at adulthood, we also found a reduced sperm motility. This may be explained not only by alterations in spermatogenesis but also by impaired epididymal maturation. This involves changes of the sperm membrane, which provides fertilisation capability and motility (Cooper 1998). Based on basic and clinical studies, we have postulated that the epididymis is a reproductive structure sensitive to nutritional alterations (Martini et al. 2007, 2010, Luque et al. 2017); whether it is also a target of foetal programming remains unexplored. However, since the differentiation of internal genitalia (including the epididymis) occurs during foetal life, it is a plausible hypothesis (reviewed in Zambrano et al. 2014).

Something similar occurs in normal ovary development during embryogenesis, which determines fertility and 
reproductive capacity later in life (reviewed in Chadio \& Kotsampasi 2014). Female sheep offspring, born from mothers undernourished from mid to late gestation, exhibited fewer corpora lutea. This may potentially affect pregnancy establishment, since the corpus luteum provides steroid hormonal support for early pregnancy (Kotsampasi et al. 2009, Chadio \& Kotsampasi 2014).

Regarding fertility conditions of female pups at adulthood, our study showed a tendency towards increased embryo loss and foetal atrophy in animals exposed to intragestational Ant and/or GHRL. As mentioned before, in an earlier study, we found that the administration of Ant or GHRL (at the same doses used in this study) during early gestation exerted negative effects on preimplantation embryo development and on implantation, evidenced as augmentation of embryo loss and foetal atrophy (Luque et al. 2014). It is interesting that a similar tendency was observed in adult females exposed to intragestational GHRL imbalances. A remarkable study by Martin et al. (2011) demonstrated a significantly lower implantation index in female mice exposed to intragestational GHRL deficiency (similar to our Ant treatment), explained by impaired endometrial function. As in our study, they did not find any alterations in ovarian follicles or corpora lutea (Martin et al. 2011). In a previous study with dams treated with GHRL or Ant from Day 3 to 7 of gestation, we demonstrated that, even though there was a significant increase in embryo loss or foetal atrophy, progesterone levels remained in normal levels (De Loredo et al. 2015).

Another important finding of our study is that GHRL imbalance during pregnancy seems to programme body weight increase until adulthood, particularly in male pups. There are some reports that intragestational treatment with GHRL exerts a significant increase in pup body weight at birth. Hayashida et al. (2002) and Nakahara et al. (2006), treating pregnant rats with GHRL from Day 14-15 to delivery, found a significant increase (of around 10\%) in initial pup body weight compared with those treated with vehicle. It is important to remark, nevertheless, that the doses of GHRL used in those studies are much higher than ours $(9 \mathrm{nmol} /$ animal/day). In fact, in contrast to our model, these doses increased daily food intake and forced researchers to pair-feed pregnant females to be able to corroborate their results (Nakahara et al. 2006). Nevertheless, administering smaller doses of GHRL to rats $(1 \mathrm{nmol} /$ animal/day) from Days 1 to 11 of pregnancy, Fernández-Fernández et al. (2005) also detected higher initial weight in pups. Additionally, they found a reduction in litter size, which may have modified foetal growth (Fernández-Fernández et al. 2005).

In an earlier study using a GHRL analogue (hexarelin $200 \mu \mathrm{g} / \mathrm{animal} / \mathrm{day})$, we observed that hexarelin, administered to mouse dams for the second or third week of pregnancy, increased body weight gain until adulthood without modifying the initial weight (Luque et al. 2010). Overall, our results suggest that the GHRL doses used in our study are not high enough to increase foetal growth during pregnancy, but are sufficient to programme body weight gain during postnatal growth. It would be interesting to evaluate pup food intake (which regretfully we did not do in this study), pup metabolism (levels of glucose, insulin, cholesterol, triglycerides, etc.) and/or the hypothalamic orexigenic system (NPY, AgRP, etc.). Variation in these parameters may explain some underlying mechanisms of the differential evolution of body weight.

Finally, the treatment of dams with GHRL or Ant during pregnancy did not modify the physical or neurobiological development of the offspring. Unfortunately, we did not find any other study that analysed these same parameters so that we could compare our results. In a previous study examining the effects of HEX administration throughout pregnancy, we did not find any differences in the parameters evaluated when compared to control subjects (Luque et al. 2010).

In summary, our results suggest that intragestational GHRL participates in reproductive foetal programming: alterations in GHRL levels (or activity) during pregnancy hasten puberty onset but exert (or tend to exert) negative effects on adult fertility. This apparent dichotomy of reproductive responses seems to be a common feature of reproductive foetal programming (Chadio \& Kotsampasi 2014, De Bond \& Smith 2014, Zambrano et al. 2014).

To our knowledge, this is the only study that explores the physiological function of GHRL in foetal programming. It should be remembered that many women at reproductive ages are underweight and/or suffer diseases such as anorexia, obesity or polycystic ovarian syndrome. Since all of these pathologies alter GHRL levels (Repaci et al. 2011, Goebel-Stengel et al. 2013), the study of GHRL as a reproductive programmer is indeed clinically relevant.

\section{Declaration of interest}

The authors declare that there is no conflict of interest that could be perceived as prejudicing the impartiality of the research reported.

\section{Funding}

This study was supported by grants from the Secretaría de Ciencia y Tecnología, Universidad Nacional de Córdoba (SECYT-UNC; 05/H383) and the Consejo Nacional de Investigaciones Científicas y Tecnológicas (CONICET; PIP 2014-2016 Gl - 11220130100380CO).

\section{Acknowledgements}

The authors thank Clarisa Lagares for the care of our experimental animals and technical support. 


\section{References}

Avendaño MS, Vazquez MJ \& Tena-Sempere M 2017 Disentangling puberty: novel neuroendocrine pathways and mechanisms for the control of mammalian puberty. Human Reproduction Update 23 737-763.

Barreiro ML, Gaytán F, Caminos JE, Pinilla L, Casanueva FF, Aguilar E, Dieguez C \& Tena-Sempere M 2002 Cellular location and hormonal regulation of ghrelin expression in rat testis. Biology of Reproduction $\mathbf{6 7}$ 1768-1776. (https://doi.org/10.1095/biolreprod.102.006965)

Barreiro M, Suominen J, Gaytan F, Pinilla L, Chopin L, Casanueva F, Dieguez C, Aguilar E, Toppari J \& Tena-Sempere M 2003 Developmental, stage-specific, and hormonally regulated expression of growth hormone secretagogue receptor messenger RNA in rat testis. Biology of Reproduction 68 1631-1640. (https://doi.org/10.1095/ biolreprod.102.008862)

Barreiro ML, Gaytán F, Castellano JM, Suominen JS, Roa J, Gaytán M, Aguilar E, Dieguez C, Toppari J \& Tena-Sempere M 2004 Ghrelin inhibits the proliferative activity of immature Leydig cells in vivo and regulates stem cell factor messenger ribonucleic acid expression in rat testis. Endocrinology 145 4825-4834. (https://doi.org/10.1210/en.2004-0732)

Bedford JM, Calvin H \& Cooper GW 1973 The maturation of the spermatozoa in the human epididymis. Journal of Reproduction and Infertility 18 199-208.

Bertoldi ML, Luque EM, Carlini VP, Vincenti LM, Stutz G, Santillán ME, Ruiz RD, Fiol de Cuneo M \& Martini AC 2011 Inhibitory effects of ghrelin on sexual behavior: role of the peptide in the receptivity reduction induced by food restriction in mice. Hormone and Metabolic Research 43 494-499. (https://doi.org/10.1055/s-0031-1277228)

Bowers WJ, Nakai JS, Chu I, Wade MG, Moir D, Yagminas A, Gill S, Pulido O \& Meuller R 2004 Early developmental neurotoxicity of a pcb/organochlorine mixture in rodents after gestational and lactational exposure. Toxicological Sciences 77 51-62. (https://doi.org/10.1093/ toxsci/kfg248)

Caminos JE, Tena-Sempere M, Gaytán F, Sánchez-Criado JE, Barreiro ML, Nogueiras R, Casanueva FF, Aguilar E \& Diéguez C 2003 Expression of ghrelin in the cyclic and pregnant rat ovary. Endocrinology $\mathbf{1 4 4}$ 1594-1602. (https://doi.org/10.1210/en.2002-221058)

Castellano JM, Bentsen AH, Sánchez-Garrido MA, Ruiz-Pino F, Romero M, García-Galiano D, Aguilar E, Pinilla L, Diéguez C, Mikkelsen JD et al. 2011 Early metabolic programming on puberty onset: impact of changes in postnatal feeding and rearing conditions on the timing of puberty and development of the hypothalamic kisspeptin system. Endocrinology 152 3396-3408. (https://doi.org/10.1210/en.2010-1415)

Cooper TG 1998 Epididymis. In Encyclopedia of Reproduction, 1st ed., pp 1-17. Eds E Knobil \& JD Neill. San Diego: Academic Press.

Cornwall GA, Vindivich D, Tillman S \& Chang TS 1988 The effects of sulfhydryl oxidation on the morphology of immature hamster epididymal spermatozoa induced to acquire motility in vitro. Biology of Reproduction 39 141-155. (https://doi.org/10.1095/biolreprod 39.1.141)

Chadio S \& Kotsampasi B 2014 The role of early life nutrition in programming of reproductive function. Journal of Developmental Origins of Health and Disease 5 2-15. (https://doi.org/10.1017/S204017441300038X)

Chanoine JP, Wong AC \& Barrios V 2006 Obestatin, acylated and total ghrelin concentrations in the perinatal rat pancreas. Hormone Research 66 81-88. (https://doi.org/10.1159/000093585)

De Bond JA \& Smith JT 2014 Kisspeptin and energy balance in reproduction. Reproduction 147 53-63. (https://doi.org/10.1530/REP-13-0509)

De Loredo N, Díaz-Luján C, Luque E, Vincenti LM, Cantarelli VI, Ponzio MF, Fretes R \& Martini AC 2015 Ghrelin modulates embryo implantation by different mechanisms: preliminary results. Placenta $\mathbf{3 6}$ 511-512.

Desai M, Gayle D, Babu J \& Ross MG 2005 Programmed obesity in intrauterine growth-restricted newborns: modulation by newborn nutrition. American Journal of Physiology: Regulatory, Integrative and Comparative Physiology 288 91-96. (https://doi.org/10.1152/ ajpregu.00340.2004)

Du C, Li H, Cao G, Wang C \& Li C 2010 Expression of the orexigenic peptide ghrelin and the type 1 a growth hormone secretagogue receptor in sheep oocytes and pre-implantation embryos produced in vitro. Reproduction in Domestic Animals 45 92-98. (https://doi.org/10.1111/ j.1439-0531.2008.01259.x)
Fernández-Fernández $R$, Tena-Sempere $M$, Navarro VM, Barreiro $M L$, Castellano JM, Aguilar E \& Pinilla L 2005 Effects of ghrelin upon gonadotropin-releasing hormone and gonadotropin secretion in adults female rats: in vivo and in vitro studies. Neuroendocrinology $\mathbf{8 2}$ 245-255. (https://doi.org/10.1159/000092753)

Fernández-Fernández R, Martini AC, Navarro VM, Castellano JM, Diéguez C, Aguilar E, Pinilla L \& Tena-Sempere M 2006 Novel signals for the integration of energy balance and reproduction. Molecular and Cellular Endocrinology 254-255 127-132. (https://doi.org/10.1016/j. mce.2006.04.026)

Fiol de Cuneo M, Ruiz R, Ponce A, Maldonado X \& Lacuara J 1994 Timerelated changes in functional activity of mouse spermatozoa during in vitro or in vivo incubation. Journal of Experimental Animal Science 36 189-200.

Fuglsang J, Skjaerbaek C, Espelund U, Frystyk J, Fisker S, Flyvbjerg A \& Ovesen P 2005 Ghrelin and its relationship to growth hormones during normal pregnancy. Clinical Endocrinology 62 554-559. (https://doi. org/10.1111/j.1365-2265.2005.02257.x)

García MC, López M, Álvarez CV, Casanueva F, Tena-Sempere M \& Dieguez C 2007 Role of ghrelin in reproduction. Reproduction 133 531-540. (https://doi.org/10.1530/REP-06-0249)

Gaytan F, Barreiro ML, Caminos JE, Chopin LK, Herington AC, Morales C, Pinilla L, Paniagua R, Nistal M \& Casanueva FF 2004 Expression of ghrelin and its functional receptor, the type 1a growth hormone secretagogue receptor, in normal human testis and testicular tumors. Journal of Clinical Endocrinology and Metabolism 89 400-409. (https:// doi.org/10.1210/jc.2003-031375)

Gaytan F, Morales C, Barreiro ML, Jeffery P, Chopin LK, Herington AC, Casanueva FF, Aguilar E, Dieguez C \& Tena-Sempere M 2005 Expression of growth hormone secretagogue receptor type 1a, the functional ghrelin receptor, in human ovarian surface epithelium, mullerian duct derivatives, and ovarian tumors. Journal of Clinical Endocrinology and Metabolism 90 1798-1804.

Genovese P, Nuñez ME, Pombo C \& Bielli A 2010 Undernutrition during foetal and post-natal life affects testicular structure and reduces the number of Sertoli cells in the adult rat. Reproduction in Domestic Animals 45 233-236. (https://doi.org/10.1111/j.1439-0531.2008.01244.x)

Goebel-Stengel M, Hofmann T, Elbelt U, Teuffel P, Ahnis A, Kobelt P, Lambrecht NW, Klapp BF \& Stengel A 2013 The ghrelin activating enzyme ghrelin-O-acyltransferase (GOAT) is present in human plasma and expressed dependent on body mass index. Peptides 43 13-19. (https://doi.org/10.1016/j.peptides.2013.02.011)

Govoni N, Parmeggiani A, Galeati G, Penazzi P, De lasio R, Pagotto U, Pasquali R, Tamanini C \& Seren E 2007 Acyl ghrelin and metabolic hormones in pregnant and lactating sows. Reproduction in Domestic Animals 42 39-43. (https://doi.org/10.1111/j.1439-0531.2006.00722.x)

Gualillo O, Caminos J, Blanco M, Garcia-Caballero T, Kojima M, Kangawa K, Dieguez C \& Casanueva F 2001 Ghrelin, a novel placentalderived hormone. Endocrinology 142 788-794. (https://doi.org/10.1210/ endo.142.2.7987)

Harrison JL, Adam CL, Brown YA, Wallace JM, Aitken RP, Lea RG \& Miller DW 2007 An immunohistochemical study of the localization and developmental expression of ghrelin and its functional receptor in the ovine placenta. Reproductive Biology and Endocrinology 5 25. (https:// doi.org/10.1186/1477-7827-5-25)

Hayashida T, Nakahara K, Mondal MS, Date Y, Nakazato M, Kojima M, Kangawa K \& Murakami N 2002 Ghrelin in neonatal rats: distribution in stomach and its possible role. Journal of Endocrinology 173 239-245. (https://doi.org/10.1677/joe.0.1730239)

Iwasa I, Matzuzaki M, Murakami S, Fujisawa R, Kinouchi G, Gereltsetseg G, Kuwahara A, Yasui T \& Irahara M 2010 Effects of intrauterine undernutrition on hypothalamic Kiss1 expression and the timing of puberty in female rats. Journal of Physiology 588 821-829. (https://doi.org/10.1113/jphysiol.2009.183558)

Kawamura K, Sato N, Fukuda J, Kodama H, Kumagai J, Tanikawa H, Nakamura A, Honda Y, Sato T \& Tanaka T 2003 Ghrelin inhibits the development of mouse preimplantation embryos in vitro. Endocrinology 144 2623-2633. (https://doi.org/10.1210/en.2003-0033)

Kihara T, Surjono TW, Sakamoto M, Matsuo T, Yasuda Y \& Tanimura T 2001 Effects of prenatal rubratoxin-b exposure on behaviors of mouse offspring. Toxicological Sciences 61 368-373. (https://doi.org/10.1093/ toxsci/61.2.368) 
Kojima M \& Kangawa K 2005 Ghrelin: structure and function. Physiological Reviews 85 495-522. (https://doi.org/10.1152/physrev.00012.2004)

Kojima M, Hosoda H, Date Y, Nakazato M, Matsuo H \& Kangawa K 1999 Ghrelin is a growth-hormone acylated peptide from stomach. Nature 402 656-666. (https://doi.org/10.1038/45230)

Kojima M, Hosoda H, Matsuo H \& Kangawa K 2001 Ghrelin: discovery of the natural endogenous ligand for the growth hormone secretagogue receptor. Trends in Endocrinology and Metabolism 12 118-122. (https:// doi.org/10.1016/S1043-2760(00)00362-3)

Kotsampasi B, Chadio S, Papadomichelakis G, Deligeorgis S, Kalogiannis D, Menegatos I \& Zervas G 2009 Effects of maternal undernutrition on the hypothalamic-pituitary-gonadal axis function in female sheep offspring. Reproduction in Domestic Animals 44 677-684. (https://doi. org/10.1111/j.1439-0531.2007.01046.x)

Kovács A \& Foote R 1992 Viability and acrosome staining of bull, boar and rabbit spermatozoa. Biotechnic and Histochemistry 67 119-124.

Larson JL \& Miller DJ 1999 Simple histochemical stain for acrosomes on sperm from several species. Molecular Reproduction and Development 52 445-449. (https://doi.org/10.1002/(SICI)10982795(199904)52:4<445::AID-MRD14>3.0.CO;2-6)

Luque EM, Carlini V, Vincenti LM, Puechagut P, Stutz G, Santillán ME Ruiz RD Martini AC \& Fiol de Cuneo M 2010 Effects of hexarelin (ghrelin analogue) on fertilization and pre-posnatal development of mice. Reproduction, Fertility and Development 22 926-938. (https://doi. org/10.1071/RD09231)

Luque EM, Torres PJ, de Loredo N, Vincenti LM, Stutz G, Santillán ME Ruiz RD, Fiol de Cuneo M \& Martini AC 2014 Role of ghrelin on the fertilization, early embryo development and implantation periods. Reproduction 148 159-167. (https://doi.org/10.1530/REP-14-0129)

Luque EM, Tissera A, Gaggino MP, Molina RI, Mangeaud A, Vincenti LM, Beltramone F, Sad Larcher, J Estofán D, Fiol de Cuneo M et al. 2017 Body mass index and human sperm quality: neither one extreme nor the other. Reproduction, Fertility and Development 29 731-739. (https://doi. org/10.1071/RD15351)

Makler A 1980 The improved ten-micrometer chamber for rapid sperm count and motility evaluation. Fertility and Sterility 33 337-338. (https:// doi.org/10.1016/S0015-0282(16)44606-6)

Martin JR, Lieber SB, McGrath J, Shanabrough M, Horvath TL \& Taylor HS 2011 Maternal ghrelin deficiency compromises reproduction in female progeny through altered uterine developmental programming. Endocrinology 152 2060-2066. (https://doi.org/10.1210/en.2010-1485)

Martini AC, Fernández-Fernández R, Tovar S, Navarro VM, Vigo E, Vázquez MJ, Davies JS, Thompson NM, Aguilar E, Pinilla L et al. 2006 Comparative analysis of the effects of ghrelin and unacylated ghrelin on luteinizing hormone secretion in male rats. Endocrinology 147 2374-2382. (https://doi.org/10.1210/en.2005-1422)

Martini AC, Molina RI, Vincenti LM, Santillán ME, Stutz G, Ruiz RD \& Fiol de Cuneo M 2007 Neutral alpha-glucosidase activity in mouse: a marker of epididymal function? Reproduction, Fertility and Development 19 563-568. (https://doi.org/10.1071/RD06070)

Martini AC, Tissera A, Estofán D, Molina RI, Mangeaud A, Fiol de Cuneo M \& Ruiz RD 2010 Overweight and seminal quality: a study in 794 patients. Fertility and Sterility 94 1739-1743. (https://doi.org/10.1016/j. fertnstert.2009.11.017)

Metz G \& Schwab ME 2004 Behavioral characterization in a comprehensive mouse test battery reveals motor and sensory impairments in growthassociated protein-43 null mutant mice. Neuroscience 129 563-574. (https://doi.org/10.1016/j.neuroscience.2004.07.053)

Nakahara K, Nakagawa M, Baba Y, Sato M, Toshinai K, Date Y, Nakazato M, Kojima M, Miyazato M, Kaiya H et al. 2006 Maternal ghrelin plays an important role in rat fetal development during pregnancy. Endocrinology 147 1333-1342. (https://doi.org/10.1210/en.2005-0708)

Orth JM, Gunsalus GL \& Lamperti AA 1988 Evidence from Sertoli celldepleted rats indicates that spermatic number in adults depend on number of Sertoli cells produced during perinatal development. Endocrinology 122 787-794. (https://doi.org/10.1210/endo-122-3-787)

Palik E, Baranyi E, Melczer Z, Audikovszky M, Szocs A, Winkler G \& Cseh K 2007 Elevated serum acylated (biologically active) ghrelin and resistin levels associate with pregnancy-induced weight gain and insulin resistance. Diabetes Research and Clinical Practice 76 351-357. (https:// doi.org/10.1016/j.diabres.2006.09.005)

Puechagut P, Martini AC, Stutz G, Santillán ME, Luque EM, Fiol de Cuneo M, Ruiz RD \& Vincenti LM 2012 Reproductive performance and fertility in male and female adult mice chronically treated with hexarelin. Reproduction, Fertility and Development 24 451-460. (https://doi. org/10.1071/RD11009)

Rabadan-Diehl C \& Nathanielsz P 2013 From mice to men: research models of developmental programming. Journal of Developmental Origins of Health and Disease 4 3-9. (https://doi.org/10.1017/ S2040174412000487)

Repaci A, Gambieri A, Pagotto U \& Pasquali R 2011 Ghrelin and reproductive disorders. Molecular and Cellular Endocrinology $\mathbf{3 4 0}$ 70-79. (https://doi.org/10.1016/j.mce.2011.02.022)

Santillán ME, Vincenti LM, Martini A,C Fiol de Cuneo, M Ruiz RD, Mangeaud A \& Stutz G 2010 Developmental and neurobehavioral effects of perinatal exposure to diets with different $n-6: n-3$ ratios in mice. Nutrition 26 423-431.

Schneider JE 2004 Energy balance and reproduction. Physiology and Behavior 81 289-317. (https://doi.org/10.1016/j.physbeh.2004.02.007)

Shibata K, Hosoda H, Kojima M, Kangawa K, Makino Y, Makino I, Kawarabayashi T, Futagami K \& Gomita Y 2004 Regulation of ghrelin secretion during pregnancy and lactation in the rat: possible involvement of hypothalamus. Peptides 25 279-287. (https://doi.org/10.1016/j. peptides.2004.01.011)

Steculorum SM \& Bouret SG 2011 Developmental effects of ghrelin. Peptides 32 2362-2366. (https://doi.org/10.1016/j.peptides.2011.06.021)

Tena-Sempere $\mathbf{M} 2008$ a Ghrelin and reproduction: ghrelin as novel regulator of the gonadotropic axis. Vitamins and Hormones 77 285-300.

Tena-Sempere $\mathbf{M} 2008 b$ Ghrelin as a pleiotrophic modulator of gonadal function and reproduction. Nature Clinical Practice Endocrinology and Metabolism 4 666-674. (https://doi.org/10.1038/ncpendmet1003)

Torres PJ, Moreno F, Luque EM, Cantarelli V, Muñoz L, Ponzio MF \& Martini AC 2017 Food restriction and fetal programming in mice: physical, neurobiological and reproductive development of litters. Revista Facultad de Ciencias Médicas Supl JIC XVIII Abstract 680.

Vorhees CV, Butcher RE, Brunner RL \& Sobotka TJ 1979 A developmental test battery for neurobehavioral toxicity in rats: a preliminary analysis using monosodium glutamate calcium carrageenan, and hydroxyurea. Toxicology and Applied Pharmacology 50 267-282. (https://doi. org/10.1016/0041-008X(79)90152-2)

Wang X, Liang L \& Du L 2007 The effects of intrauterine undernutrition on pancreas ghrelin and insulin expression in neonate rats. Journal of Endocrinology 194 121-129. (https://doi.org/10.1677/JOE-07-0057)

Yoshida S, Numachi Y, Matsuoka H \& Sato M 2000 The absence of impairment of cliff avoidance reaction induced by subchronic methamphetamine treatment in inbred strains of mice. Tohoku Journal of Experimental Medicine 190 205-212. (https://doi.org/10.1620/ tjem.190.205)

Zambrano E, Guzmán C, Rodríguez-González GL, Durand-Carabajal M \& Nathanielsz PW 2014 Fetal programming of sexual development and reproductive function. Molecular and Cellular Endocrinology 382 538-549. (https://doi.org/10.1016/j.mce.2013.09.008)

Zhang K, Wei HX, Zhang YH, Wang SH, Li Y, Dai YP \& Li N 2007 Effects of ghrelin on in vitro development of porcine in vitro fertilized and parthenogenetic embryos. Journal of Reproduction and Development $\mathbf{5 3}$ 647-653. (https://doi.org/10.1262/jrd.18140)

Received 12 April 2018

First decision 9 May 2018

Revised manuscript received 3 July 2018

Accepted 10 July 2018 